Arq. Bras. Med. Vet. Zootec., v.60, n.1, p.139-147, 2008

\title{
Características da carcaça e da carne de bovinos sob diferentes dietas, e m confinamento
}

[Carcass and meat characteristic of cattle receiving differents diets in feedlot]

\author{
A.R.M. Fernandes ${ }^{1,5}$, A.A.M. Sampaio ${ }^{2,6^{*}}$, W. Henrique ${ }^{3}$, E. A. Oliveira ${ }^{1,6}$, R. R. Tullio ${ }^{4}$, D. Perecin ${ }^{2,6}$ \\ ${ }^{1}$ Aluno de pós-graduação - FCAV-UNESP - Jaboticabal, SP \\ ${ }^{2}$ Faculdade de Ciências Agrárias e Veterinárias - UNESP \\ Via de acesso Prof. Paulo Donato Castellane, $\mathrm{s} / \mathrm{n}$ \\ 14884-900 - Jaboticabal, SP \\ ${ }^{3}$ Agência Paulista de Tecnologia dos Agronegócios - São José do Rio Preto, SP \\ ${ }^{4}$ Embrapa Pecuária Sudeste - São Carlos, SP \\ ${ }^{5}$ Bolsista da FAPESP \\ ${ }^{6}$ Bolsista do $\mathrm{CNPq}$
}

\begin{abstract}
RESUMO
Avaliaram-se as características qualitativas da carcaça e da carne de 10 tourinhos, de 10 machos castrados e de 10 fêmeas da raça Canchim, terminados em confinamento e alimentados com: 1 - silagem de milho e concentrado contendo farelo de soja, milho e polpa cítrica (SM) e 2 - cana-de-açúcar e concentrado contendo farelo de soja, milho, grãos de girassol e polpa cítrica (CA). O período experimental foi de 105 dias, e o delineamento foi o inteiramente ao acaso, em esquema fatorial $3 \times 2$ ( 3 condições sexuais e 2 dietas). Não foram observadas interações e os tourinhos apresentaram maiores $(\mathrm{P}<0,05)$ peso da carcaça quente e da área de olho de lombo, maior rendimento de dianteiro e menor rendimento de traseiro em relação aos machos castrados e às fêmeas. Nas amostras de contrafilé, não houve diferença entre tratamentos quanto à força de cisalhamento, $\mathrm{pH}$, perdas totais por gotejamento e capacidade de retenção de água e cor da carne. Os machos castrados e as fêmeas apresentaram carne de melhor textura. As dietas SM e CA podem ser utilizadas na terminação de bovinos em confinamento.
\end{abstract}

Palavras chave: bovino de corte, Canchim, categoria animal, rendimento de carcaça, degustação

\section{ABSTRACT}

The carcass and meat qualitative characteristics of 10 young bulls, 10 castrated males, and 10 females of Canchim breed finished in feedlot were evaluated. Animals were fed: 1 - corn silage and concentrate containing soybean meal, corn and citrus pulp (CS), and 2 - sugar cane and concentrate containing soybean meal, corn, sunflower grains, and citrus pulp (SC). The data were analized by completely randomized design in a factorial $3 \times 2$ arrangement (three sexual conditions $x$ two diets), and the experimental period lasted 105 days. No interactions were observed and the young bulls presented higher $(P<0.05)$ hot carcass weights and loin area, higher hindquarter and lower forequarter yields in relation to the castrated males and females. The samples of loin did not show differences among treatments in relation to shear force, $\mathrm{pH}$, total losses due dripping on capacity of water retention, and meat color. The castrated males and females presented better texture of meat. The CS and SC diets can be used in finishing cattle under confinement.

Keywords: beef cattle, Canchim, animal category, carcass yield, tasting

Recebido em 13 de julho de 2006

Aceito em 19 de novembro de 2007

*Autor para correspondência (corresponding author)

E-mail: sampaio@fcav.unesp.br 


\section{INTRODUÇÃO}

O êxito da produção de bovinos jovens caminha para a obtenção de carcaça com melhor qualidade e de carne com características diferenciadas. No mercado internacional, um dos principais problemas de recusa da carne brasileira está diretamente ligado às características de conservação, falta de padronização do produto, ou mesmo pela pouca maciez (Arrigoni, 2003). Nos anos mais recentes, a pesquisa evoluiu no sentido de investigar e melhorar os aspectos qualitativos dos produtos cárneos, com o objetivo de ampliar a competição no mercado externo, que tem sido a grande alavanca incentivadora dessa atividade.

Vaz e Restle (2005) avaliaram a cana-de-açúcar e a silagem de milho na alimentação de novilhos Hereford em confinamento, e não observaram diferenças nas características qualitativas da carne, porém os animais alimentados com silagem de milho apresentaram carcaças mais pesadas. Brondani et al. (2006) observaram maior rendimento de carcaça para animais alimentados com silagem de milho em relação aos alimentados com cana-de-açúcar, não sendo detectadas diferenças quanto à qualidade da carne. Restle et al. (2001), ao estudarem novilhas da raça Charolês e mestiças $3 / 4$ Charolesa $x 1 / 4$ Nelore, terminadas em confinamento, observaram maior rendimento de traseiro e carne de maior suculência nas novilhas Charolês. Junqueira et al. (1998) verificaram que novilhas cruzadas Marchigiana $x$ Nelore, terminadas em confinamento, apresentaram maiores rendimentos de alcatra, picanha, filé e contrafilé que machos não castrados, do mesmo grupo genético, porém os machos apresentaram maior rendimento de carcaça. Em razão desses resultados, os autores relataram que a desvalorização comercial das fêmeas não se justifica.

O objetivo do presente trabalho foi avaliar as características da carcaça e a qualidade da carne de bovinos da raça Canchim, de várias condições sexuais e alimentados com silagem de milho e concentrado contendo farelo de soja ou com canade-açúcar e concentrado contendo farelo de soja e grãos de girassol.

\section{MATERIAL E MÉTODOS}

Foram utilizados 30 animais da raça Canchim com aproximadamente 15 meses de idade e peso corporal médio de $289 \pm 16 \mathrm{~kg}$, sendo 10 tourinhos, 10 machos castrados e 10 fêmeas. Os animais de cada condição sexual foram distribuídos em uma das duas dietas avaliadas.

As dietas, apresentadas na Tab. 1, foram formuladas pelo sistema RLM ${ }^{\circledR} /$ Esalq-USP, sendo o balanceamento realizado de acordo com o sistema CNCPS, desenvolvido por Fox et al. (1992). A variedade de cana-de-açúcar utilizada na dieta CA foi a forrageira IAC 86-2480, que apresenta boa produtividade, alto teor de açúcar e baixo teor de fibra, conforme descrito por Landell et al. (2002). Para suprir as deficiências nutricionais e aumentar a densidade energética, foram incluídos, no concentrado, grãos de girassol (Helianthus annuus), contendo 39\% de óleo e $30 \%$ de proteína bruta. O fornecimento ocorreu, diariamente, às 8 e 14h, observando-se a quantidade de $10 \%$ de sobras para caracterização de consumo ad libitum, seguindo as recomendações de Sampaio et al. (1998).

Após atingirem o ponto adequado de acabamento de16@para os machos e15@para as fêmeas, com cobertura de gordura de no mínimo 3mm, avaliada por ultra-som, os animais foram abatidos, adotando-se os procedimentos de rotina. Foram obtidos os pesos de carcaça quente, das gorduras pélvica, perirenal e inguinal, e o comprimento da carcaça, além de calculado o rendimento de carcaça. As meiascarcaças foram levadas à câmara fria a $4^{\circ} \mathrm{C}$ por, aproximadamente, 24 horas e, em seguida, pesadas para a obtenção do peso da carcaça resfriada. As carcaças, divididas em traseiro e dianteiro, foram separadas entre a quinta e a sexta costela. Do traseiro, a uma distância de $20 \mathrm{~cm}$ da coluna vertebral, foi retirada a ponta de agulha, que constituiu o traseiro especial. Os cortes foram pesados para $\mathrm{o}$ cálculo de rendimento em relação à carcaça resfriada.

$\mathrm{Na}$ meia-carcaça esquerda, foi realizado um corte transversal entre a $12^{\mathrm{a}}$ e $13^{\mathrm{a}}$ costelas, de maneira a expor o músculo longissimus. Foi então tomada a medida da espessura de gordura, obtida no terceiro quarto da altura desse músculo a partir da coluna vertebral, com o auxílio de uma régua de precisão, e feito o desenho do perímetro do músculo, em papel vegetal. A área de olho de lombo foi medida com utilização de um planímetro, seguindo as recomendações de Tullio (2004). 
Tabela 1. Composição percentual, na matéria seca, e perfil nutricional das dietas oferecidas a bovinos de corte de várias categorias

\begin{tabular}{lcc}
\hline \multicolumn{1}{c}{ Ingrediente } & \multicolumn{2}{c}{ Dieta } \\
\cline { 2 - 3 } \multicolumn{1}{c}{ Cana-de-açúcar } & SM & CA \\
Silagem de milho & - & 40,00 \\
Grãos de girassol & 40,00 & - \\
Farelo de soja & - & 11,30 \\
Milho em grão moído & 10,60 & 13,65 \\
Polpa cítrica & 35,50 & 22,15 \\
Núcleo mineral & 11,00 & 10,00 \\
Uréia & 1,00 & 1,00 \\
Bicarbonato de sódio & 0,40 & 0,40 \\
\hline Perfil nutricional ${ }^{1}$ & 1,50 & 1,50 \\
\hline MS (\%) & & \\
PB (\% da MS) & 51,00 & 48,00 \\
NDT (\% da MS) & 14,00 & 14,05 \\
EM (MJ/kg MS) & 75,00 & 74,00 \\
EE (\% da MS) & 11,68 & 11,52 \\
\hline SM: & 3,10 & 4,10 \\
\hline
\end{tabular}

SM: dieta com silagem de milho e concentrado contendo farelo de soja; CA: dieta com cana-de-açúcar e concentrado contendo farelo de soja e grãos de girassol.

MS: matéria seca; PB: proteína bruta; EE: extrato etéreo; NDT: nutrientes digestíveis totais; EM: energia metabolizável.

${ }^{1}$ Estimativas segundo o sistema $\operatorname{RLM}^{\mathbb{R}}$ de formulação de dietas.

Após as medições, foram retiradas duas amostras do contrafilé na altura da $12^{\underline{a}}$ costela, com aproximadamente $2,5 \mathrm{~cm}$ de espessura, para determinação das características qualitativas, seguindo os procedimentos descritos por Tullio (2004). As determinações da cor da carne e da gordura foram realizadas por meio de colorímetro, avaliando-se a luminosidade $\left(\mathrm{L}^{*} 0=\right.$ preto; $100=$ branco ), a intensidade da cor vermelha $\left(\mathrm{a}^{*}\right)$ e a intensidade da cor amarela (b*). Trinta minutos antes das avaliações e em pontos diferentes da carne, foi realizado um corte transversal ao músculo, para exposição da mioglobina ao oxigênio. A calibração do aparelho foi realizada antes da leitura das amostras com um padrão branco e outro preto.

A capacidade de retenção de água foi obtida por diferença entre os pesos de uma amostra de carne, de aproximadamente $2 \mathrm{~g}$, antes e depois de ser submetida à pressão de $10 \mathrm{~kg}$, durante cinco minutos.

Os bifes, obtidos do contrafilé, foram assados em forno a gás à temperatura de $175^{\circ} \mathrm{C}$, até atingir $75^{\circ} \mathrm{C}$ no seu centro geométrico. Os pesos dos bifes antes e depois da cocção foram utilizados para o cálculo das perdas totais, enquanto os pesos das bandejas, antes e após a cocção, foram obtidos para a determinação das perdas por gotejamento. Após o resfriamento dos bifes assados, foram retirados oito cilindros, utilizando-se um vazador com $2 \mathrm{~cm}$ de diâmetro, para determinar a força necessária para cortar transversalmente cada cilindro em texturômetro acoplado à lâmina Warner-Bratzler. Foi, então, calculada a média de força de corte dos cilindros para representar a força de cisalhamento de cada amostra, como descrito por Vaz e Restle (2005).

Para a análise sensorial, os bifes restantes de cada amostra foram também assados, resfriados e cortados em cubos para serem servidos a 30 degustadores. Nesse teste, foram avaliados os atributos sabor, textura, preferência e aparência geral. As notas variaram de 1 a 9 , sendo 1 a desaprovação máxima, e 9 a aprovação máxima.

Os resultados das variáveis obtidas foram avaliados segundo um delineamento inteiramente ao acaso, em esquema fatorial $3 \times 2$ (condições sexuais $\mathrm{x}$ dietas). As médias foram comparadas pelo teste Tukey a $5 \%$ de probabilidade. Para as características de sabor, textura, aparência e aspecto geral da carne foi utilizado o teste não paramétrico Kruskal-Wallis, conforme recomendado por Sampaio (2002). 


\section{Fernandes et al.}

\section{RESULTADOS E DISCUSSÃO}

Os resultados das características da carcaça considerando os efeitos da condição sexual e da dieta são apresentados na Tab. 2. Não foi observado efeito da interação $(\mathrm{P}>0,05)$ condição sexual e dieta.

Os tourinhos apresentaram $(\mathrm{P}<0,05)$ maior peso de abate (PA), maiores pesos da carcaça quente
(PCQ) e fria (PCF) em relação aos machos castrados e às fêmeas, independentemente do tipo de alimentação recebida no confinamento. Conforme descrito por Luchiari Filho (2000), tourinhos apresentam melhor desempenho que machos castrados e fêmeas e, também, são mais eficientes em converter os nutrientes da dieta em ganho de peso, resultando em carcaças mais pesadas ao abate.

Tabela 2. Peso de abate (PA), peso de carcaça quente (PCQ), rendimento de carcaça quente (RC), peso de carcaça fria (PCF), comprimento de carcaça (CC), área de olho de lombo (AOL), área de olho de lombo/100kg de carcaça fria (AOL \%) e espessura de gordura de cobertura (EGC) de bovinos Canchim terminados em confinamento, segundo o tratamento

\begin{tabular}{|c|c|c|c|c|c|c|c|c|}
\hline \multirow{2}{*}{ Variável } & \multicolumn{3}{|c|}{ Condição sexual } & \multirow[b]{2}{*}{$\mathrm{P}$} & \multicolumn{2}{|c|}{ Dieta } & \multirow[b]{2}{*}{1} & \multirow[b]{2}{*}{$\mathrm{CV}(\%)$} \\
\hline & $\mathrm{T}$ & $\mathrm{MC}$ & FM & & SM & $\mathrm{CA}$ & & \\
\hline PA (kg) & $468,80 \pm 21,79 a$ & $427,20 \pm 36,75 b$ & $416,80 \pm 18,34 b$ & 0,01 & $432,13 \pm 27,45$ & $443,06 \pm 23,80$ & 0,28 & 6,21 \\
\hline PCQ (kg) & $253,85 \pm 14,97 \mathrm{a}$ & $229,55 \pm 22,19 b$ & $220,60 \pm 12,52 b$ & 0,02 & $229,16 \pm 10,72$ & $240,17 \pm 16,88$ & 0,09 & 7,29 \\
\hline $\mathrm{RC}(\%)$ & $54,13 \pm 1,58$ & $53,72 \pm 1,80$ & $52,89 \pm 1,89$ & 0,33 & $52,94 \pm 1,96$ & $54,22 \pm 1,56$ & 0,07 & 3,49 \\
\hline PCF (kg) & $231,88 \pm 14,55 \mathrm{a}$ & $208,32 \pm 23,15 b$ & $198,55 \pm 12,41 b$ & 0,01 & $207,28 \pm 16,12$ & $218,55 \pm 16,68$ & 0,08 & 8,16 \\
\hline $\mathrm{CC}(\mathrm{m})$ & $1,32 \pm 0,028$ & $1,30 \pm 0,033$ & $1,34 \pm 0,035$ & 0,84 & $1,32 \pm 0,029$ & $1,33 \pm 0,035$ & 0,66 & 2,67 \\
\hline $\operatorname{AOL}\left(\mathrm{cm}^{2}\right)$ & $82,64 \pm 10,92 a$ & $73,95 \pm 6,09 \mathrm{ab}$ & $71,15 \pm 4,23 b$ & 0,02 & $77,28 \pm 9,00$ & $74,55 \pm 5,16$ & 0,35 & 10,35 \\
\hline AOL $(\%)$ & $38,12 \pm 5,44$ & $37,28 \pm 1,84$ & $35,97 \pm 3,13$ & 0,32 & $35,34 \pm 2,70 b$ & $38,90 \pm 4,23 a$ & 0,04 & 10,74 \\
\hline $\mathrm{EGC}(\mathrm{mm})$ & $4,3 \pm 0,79$ & $5,6 \pm 1,60$ & $5,3 \pm 1,02$ & 0,07 & $5,26 \pm 1,43$ & $4,86 \pm 0,84$ & 0,38 & 24,43 \\
\hline
\end{tabular}

Médias seguidas de letras diferentes, na mesma linha, diferem entre si pelo teste Tukey $(\mathrm{P}<0,05)$.

T: tourinho; MC: macho castrado; FM: fêmea.

SM: dieta com silagem de milho e concentrado contendo farelo de soja; CA: dieta com cana-de-açúcar e concentrado contendo farelo de soja e grãos de girassol.

P: probabilidade; CV: coeficiente de variação.

Não foram verificadas diferenças $(\mathrm{P}>0,05)$ no rendimento de carcaça quente (RC) e no comprimento de carcaça (CC), quando avaliadas as condições sexuais e as dietas. Henrique et al. (2004), ao avaliarem tourinhos Santa Gertrudes terminados em confinamento, abatidos com média de peso de $449,4 \mathrm{~kg}$, obtiveram $\mathrm{RC}$ de 53,6\%. Vaz e Restle (2005) estudaram machos castrados da raça Hereford, abatidos com média de peso de $433,5 \mathrm{~kg}$, e observaram médias de RC de 50,1 e $51,5 \%$ para animais alimentados com dietas com cana-de-açúcar e silagem de milho, respectivamente. Restle et al. (2001) avaliaram as carcaças de novilhas 3/4 Charolês x $1 / 4$ Nelore, terminadas em confinamento, e observaram RC de $51,6 \%$. Os resultados obtidos no presente trabalho sugerem que animais da raça Canchim, independentemente da condição sexual, podem apresentar bons rendimentos de carcaça em relação a outras raças utilizadas em sistemas de produção intensiva.

Tullio (2004) avaliou animais de diferentes grupos genéticos e observou que os tourinhos apresentaram maior CC que os castrados,
$1,25 \times 1,21 \mathrm{~m}$, respectivamente. Junqueira et al. (1998) verificaram que tourinhos cruzados Marchigiana x Nelore apresentaram carcaças de maior comprimento que as fêmeas provenientes do mesmo cruzamento, 1,28 e $1,21 \mathrm{~m}$, respectivamente. Os valores observados no presente trabalho, que avaliou animais puros da raça Canchim, foram mais altos e, provavelmente, estão relacionados ao tipo biológico estudado, pois, segundo Tullio (2004), a maior participação de genótipo Bos indicus nos cruzamentos resulta em tendência de menor comprimento de carcaça.

Foram verificadas diferenças $(\mathrm{P}<0,05)$ entre os valores de área de olho de lombo (AOL) segundo a condição sexual estudada. Os tourinhos apresentaram maiores médias que as fêmeas. De acordo com Luchiari Filho (2000), a AOL representa o grau de desenvolvimento muscular dos animais e está relacionada com o rendimento dos cortes de maior valor comercial. Os machos castrados apresentaram valores de AOL intermediários entre tourinhos e fêmeas. A média observada para os tourinhos no presente estudo 
foi $38 \%$ acima da apresentada por Henrique et al. (2004), porém os animais foram abatidos com maior idade e apresentaram maior peso de carcaça. Jorge et al. (1999) obtiveram média de $57,95 \mathrm{~cm}^{2}$ de $\mathrm{AOL}$, com animais zebuínos não castrados e abatidos com $450 \mathrm{~kg}$. Esse valor foi cerca de 30\% menor que o de animais mestiços, não castrados, utilizados no presente trabalho. Junqueira et al. (1998) observaram média de $\mathrm{AOL}$ de $72 \mathrm{~cm}^{2}$ em fêmeas cruzadas Marchigiana $\mathrm{x}$ Nelore, valor próximo ao observado no presente estudo. Os resultados observados na literatura indicam que o sexo e a raça dos animais apresentam grande influência sobre essa característica. Tourinhos de raças de grande porte, especializadas para a produção de carne, apresentam maior desenvolvimento muscular e conseqüentemente maior AOL.

Não foram observadas diferenças na AOL/100kg de carcaça fria (AOL \%) quando consideradas as condições sexuais, porém a dieta CA proporcionou maior valor $(\mathrm{P}<0,05)$ para esta variável. Este resultado pode estar associado ao peso médio da carcaça, 5,2\% maior, em valores absolutos, em relação à dieta $\mathrm{SM}$.

A espessura de gordura de cobertura (EGC) não variou entre os tratamentos $(\mathrm{P}>0,05)$, e este resultado pode estar associado à idade dos animais, pois, conforme Berg e Butterfield (1976), a deposição de gordura tem seu maior incremento em estágio mais avançado de desenvolvimento do animal. Durante a fase de crescimento, como no caso dos animais do presente estudo, a gordura é o tecido que apresenta menor deposição, dessa forma, não foi influenciada pelos tratamentos.

A deposição de gordura foi menor que a observada por Nardon et al. (2001), que verificaram média de $8,6 \mathrm{~mm}$, para animais abatidos com idade semelhante à deste experimento. Esses autores estudaram animais da raça Nelore, que apresentam maior potencial de deposição de gordura subcutânea na carcaça, quando comparados a animais de raças européias continentais e seus cruzamentos, como no caso da raça Canchim, que apresenta $62,5 \%$ de genótipo da raça Charolesa.

$\mathrm{Na}$ Tab. 3, apresentam-se os pesos e proporções dos cortes primários em relação à carcaça resfriada e os pesos do fígado, rins e gordura perirenal-pélvica-inguinal. Não foi verificado efeito da interação $(\mathrm{P}>0,05)$ condição sexual e dieta para essas variáveis.

Tabela 3. Peso de traseiro (PT), rendimento de traseiro (RT), peso de dianteiro (PD), rendimento de dianteiro (RD), peso de ponta de agulha (PPA), rendimento de ponta de agulha (RPA), peso do fígado $(\mathrm{PF})$, peso dos rins (PR), peso da gordura visceral (PGV) de bovinos Canchim terminados em confinamento, segundo o tratamento

\begin{tabular}{|c|c|c|c|c|c|c|c|c|}
\hline \multirow{2}{*}{ Variável } & \multicolumn{3}{|c|}{ Condição sexual } & \multirow[b]{2}{*}{$P$} & \multicolumn{2}{|c|}{ Dieta } & \multirow{2}{*}{$P$} & \multirow{2}{*}{$\mathrm{CV}(\%)$} \\
\hline & $\mathrm{T}$ & $\mathrm{MC}$ & FM & & SM & $\mathrm{CA}$ & & \\
\hline PT (kg) & $115,9836 a$ & $107,13 \pm 11,23 \mathrm{ab}$ & $104,81 \pm 5,83 b$ & 0,01 & $112,16 \pm 8,30$ & $106,45 \pm 8,18$ & 0,08 & 7,82 \\
\hline $\mathrm{RT}(\% \mathrm{CF})$ & $50,04 \pm 1,17 \mathrm{c}$ & $51,47 \pm 1,22 b$ & $52,78 \pm 0,99 \mathrm{a}$ & 0,01 & $51,37 \pm 0,95$ & $51,48 \pm 1,31$ & 0,79 & 2,27 \\
\hline $\mathrm{PD}(\mathrm{kg})$ & $88,46 \pm 5,61 \mathrm{a}$ & $76,31 \pm 9,08 \mathrm{~b}$ & $68,93 \pm 5,55 b$ & 0,01 & $79,66 \pm 7,44$ & $76,13 \pm 6,04$ & 0,17 & 8,98 \\
\hline $\mathrm{RD}(\% \mathrm{CF})$ & $38,17 \pm 0,92 \mathrm{a}$ & $36,61 \pm 1,06 \mathrm{~b}$ & $34,71 \pm 1,14 \mathrm{c}$ & 0,01 & $36,39 \pm 1,39$ & $36,60 \pm 0,69$ & 0,62 & 3,17 \\
\hline PPA (kg) & $27,41 \pm 3,15$ & $23,88 \pm 4,82$ & $24,81 \pm 2,72$ & 0,11 & $26,72 \pm 2,88$ & $24,00 \pm 4,24$ & 0,06 & 14,82 \\
\hline RPA $(\% \mathrm{CF})$ & $11,81 \pm 0,97$ & $11,92 \pm 1,06$ & $12,48 \pm 1,02$ & 0,32 & $12,23 \pm 1,02$ & $11,90 \pm 1,01$ & 0,40 & 8,65 \\
\hline $\mathrm{PF}(\mathrm{kg})$ & $5,78 \pm 0,44 a$ & $5,47 \pm 0,63 a$ & $4,71 \pm 0,32 b$ & 0,03 & $5,43 \pm 0,55$ & $5,21 \pm 0,38$ & 0,25 & 9,53 \\
\hline PR (kg) & $0,87 \pm 0,13 \mathrm{a}$ & $0,77 \pm 0,10 \mathrm{ab}$ & $0,74 \pm 0,09 b$ & 0,03 & $0,81 \pm 0,12$ & $0,78 \pm 0,09$ & 0,43 & 14,01 \\
\hline PGV (kg) & $7,08 \pm 1,41 \mathrm{~b}$ & $8,31 \pm 2,56 \mathrm{ab}$ & $9,71 \pm 1,83 \mathrm{a}$ & 0,02 & $8,14 \pm 2,13$ & $8,59 \pm 1,74$ & 0,54 & 24,27 \\
\hline
\end{tabular}

Médias seguidas de letras diferentes, na mesma linha, diferem entre si pelo teste Tukey $(\mathrm{P}<0,05)$.

T: tourinho; MC: macho castrado; FM: fêmea.

SM: dieta com silagem de milho e concentrado contendo farelo de soja; CA: dieta com cana-de-açúcar e concentrado contendo farelo de soja e grãos de girassol.

P: probabilidade; CV: coeficiente de variação.

Não foram verificadas diferenças $(\mathrm{P}>0,05)$ nos pesos e nos rendimentos de traseiro, dianteiro e ponta de agulha, quando avaliadas as dietas oferecidas. Foram observadas diferenças $(\mathrm{P}<0,05)$ no peso de traseiro dos tourinhos em relação ao das fêmeas, $115,98 \times 104,81 \mathrm{~kg}$, e o peso do traseiro dos machos castrados apresentou valor intermediário. Com relação ao rendimento de traseiro, os valores nas fêmeas foram 5,2 e 2,5 $\%$ maiores que nos machos e nos machos castrados, respectivamente. Essas diferenças inverteram-se quando foram avaliados o peso e o rendimento do dianteiro, isto é, os tourinhos apresentaram valores mais elevados $(\mathrm{P}<0,05)$. 


\section{Fernandes et al.}

Estas observações estão associadas às características de crescimento dos animais segundo a condição sexual. Os tourinhos apresentam maior desenvolvimento de tecido muscular no dianteiro que os animais castrados e as fêmeas. Esse crescimento diferenciado, de acordo com Luchiari Filho (2000), é influenciado pela presença de andrógenos gonadotróficos, necessários para completar totalmente os padrões de desenvolvimento muscular.

Não foram observadas diferenças $(\mathrm{P}>0,05)$ nos valores de peso e rendimento de ponta de agulha tanto para as dietas, quanto para as condições sexuais. O mesmo fora observado por Tullio (2004), ao relatar que possíveis diferenças no rendimento de ponta de agulha podem estar associadas à falta de padronização na retirada desse corte do traseiro.

A avaliação do peso de fígado mostrou que os machos inteiros e castrados apresentaram maiores valores $(\mathrm{P}<0,05)$ que as fêmeas, contudo não foi detectada diferença $(\mathrm{P}>0,05)$ entre dietas. Da mesma forma, não foi detectada diferença no peso dos rins segundo a dieta, mas houve influência da condição sexual. Nesse caso, o peso dos rins nos machos foi maior.
Provavelmente, essas observações estão diretamente relacionadas com o tamanho corporal dos animais dentro de cada condição sexual avaliada.

$\mathrm{O}$ peso da gordura visceral foi maior $(\mathrm{P}<0,05)$ nas fêmeas que nos tourinhos; os machos castrados apresentaram valor intermediário, que não diferiu do valor das outras duas condições sexuais. Não foi detectado efeito $(\mathrm{P}>0,05)$ do tipo da dieta sobre o peso de gordura visceral. De acordo com Luchiari Filho (2000), as fêmeas alcançam a maturidade fisiológica antes que os machos, diminuindo, assim, a deposição do tecido muscular e potencializando o acúmulo de gordura, sendo a gordura visceral depositada mais precocemente. Isso foi confirmado neste estudo.

$\mathrm{Na}$ Tab. 4 estão apresentadas as características qualitativas da carne de bovinos Canchim, segundo os tratamentos. Não foram observados efeitos da interação $(\mathrm{P}>0,05)$ condição sexual e dieta. A força de cisalhamento (FC) não variou $(\mathrm{P}>0,05)$ segundo a condição sexual e a dieta oferecida.

Tabela 4. Força de cisalhamento (FC), pH, perdas no cozimento (PCOZ), perdas por gotejamento (PGOT) e capacidade de retenção de água (CRA) da carne do contrafilé de bovinos Canchim terminados em confinamento, segundo o tratamento

\begin{tabular}{|c|c|c|c|c|c|c|c|c|}
\hline \multirow[b]{2}{*}{ Característica } & \multicolumn{3}{|c|}{ Condição sexual } & \multirow[b]{2}{*}{$\mathrm{P}$} & \multicolumn{2}{|c|}{ Dieta } & \multirow[b]{2}{*}{$\mathrm{P}$} & \multirow[b]{2}{*}{$\mathrm{CV}(\%)$} \\
\hline & $\mathrm{T}$ & $\mathrm{MC}$ & FM & & SM & $\mathrm{CA}$ & & \\
\hline $\mathrm{FC}\left(\mathrm{kg} / \mathrm{cm}^{2}\right)$ & $3,83 \pm 0,98$ & $3,09 \pm 1,32$ & $3,66 \pm 1,23$ & 0,37 & $3,66 \pm 1,04$ & $3,39 \pm 1,31$ & 0,55 & 34,41 \\
\hline $\mathrm{pH}$ & $5,69 \pm 0,12$ & $5,65 \pm 0,15$ & $5,70 \pm 0,08$ & 0,72 & $5,63 \pm 0,10$ & $5,73 \pm 0,13$ & 0,09 & 2,68 \\
\hline PCOZ (\%) & $37,03 \pm 5,96$ & $36,56 \pm 4,67$ & $32,36 \pm 3,15$ & 0,07 & $36,73 \pm 3,93$ & $33,90 \pm 5,25$ & 0,12 & 13,70 \\
\hline PGOT $(\%)$ & $34,71 \pm 5,96$ & $33,92 \pm 4,67$ & $29,70 \pm 3,30$ & 0,07 & $34,13 \pm 4,09$ & $31,42 \pm 5,20$ & 0,14 & 14,89 \\
\hline CRA $(\%)$ & $71,37 \pm 2,61$ & $73,05 \pm 1,28$ & $72,51 \pm 1,17$ & 0,19 & $72,19 \pm 1,27$ & $72,43 \pm 2,10$ & 0,74 & 2,83 \\
\hline
\end{tabular}

T: tourinho; MC: macho castrado; FM: fêmea.

SM: dieta com silagem de milho e concentrado contendo farelo de soja; CA: dieta com cana-de-açúcar e concentrado contendo farelo de soja e grãos de girassol.

P: probabilidade; CV: coeficiente de variação.

Abularach et al. (1998) observaram média de $6,70 \mathrm{~kg} / \mathrm{cm}^{2}$ para animais Nelore abatidos com idade entre 23 e 29 meses. No trabalho de Restle et al. (2001), o valor médio obtido para a FC foi de $6,24 \mathrm{~kg} / \mathrm{cm}^{2}$ para novilhas $3 / 4$ Charolês x $1 / 4$ Nelore. Segundo Lawrie (2005), valores acima de $5,00 \mathrm{~kg} / \mathrm{cm}^{2}$ caracterizam a carne como dura.

Os resultados foram mais baixos que os observados por Tullio (2004), que trabalhou com animais em confinamento de diferentes grupos genéticos, castrados ou não, e observou valor médio de $4,91 \mathrm{~kg} / \mathrm{cm}^{2}$ para a FC. Esse autor utilizou maior proporção da raça Nelore nos diferentes cruzamentos estudados, o que pode ter influenciado o resultado.

Não foram observadas diferenças $(\mathrm{P}>0,05)$ no $\mathrm{pH}$, cujo valor médio, de 5,68, permaneceu em um patamar considerado ideal segundo Cruz (1997), considerando a condição sexual e o tipo de dieta. De acordo com esse autor, a carne pode apresentar-se escura quando o $\mathrm{pH}$ está acima de 6,0 , devido à maior atividade enzimática, maior 
retenção de água e menor penetração de oxigênio.

Vaz e Restle (2000) observaram médias de pH de 5,51 para animais castrados, semelhante ao observado neste ensaio. Esses autores verificaram que o $\mathrm{pH}$ da carne de tourinhos era de 6,21. De acordo com Gregory (1998), tourinhos mantidos em confinamento são mais susceptíveis ao estresse que animais criados extensivamente. Essa condição pode contribuir para que a redução do $\mathrm{pH}$ após o resfriamento não seja efetiva. Segundo esse autor, animais submetidos a condições de estresse consomem mais glicogênio muscular antes do abate, dessa forma, a produção de ácido lático pela degradação do glicogênio, responsável pela redução do $\mathrm{pH}$, é menor.

O pH 6,0 é considerado como um divisor entre o corte normal e o dark-cutting. No Brasil, os frigoríficos exportam apenas a carne que apresenta $\mathrm{pH}$ abaixo de 5,8, avaliado diretamente no músculo longissimus, 24 horas post-morten.

As variáveis relacionadas às perdas totais, perdas por gotejamento, perdas por evaporação e capacidade de retenção de água (CRA) não diferiram entre tratamentos $(\mathrm{P}>0,05)$, porém os valores observados permaneceram em níveis adequados. Tullio (2004) encontrou média de $74,4 \%$ para a CRA, quando se considerou o grupo de animais terminados em confinamento.
Esse mesmo autor relatou que a carne de tourinhos apresentou maior CRA que a de animais castrados, contudo isso não foi observado no presente trabalho, quando consideradas as duas condições sexuais.

Os resultados referentes às análises de cor da carne e da gordura são apresentados na Tab.5. Não foram observados efeitos da interação $(\mathrm{P}>0,05)$ condição sexual e dieta estudada.

A cor da carne apresentou média de luminosidade $\left(\mathrm{L}^{*}\right)$ de 37,69 , e não foram observadas diferenças $(\mathrm{P}>0,05)$ quando se consideraram a condição sexual e o tipo de dieta. Ribeiro et al. (2002) trabalharam com tourinhos em confinamento e observaram valor de 36,99 para essa variável. A intensidade de vermelho $\left(\mathrm{a}^{*}\right)$ também não foi influenciada $(\mathrm{P}>0,05)$ pelas condição sexual e pela dieta.

O valor médio de $\mathrm{a}^{*}$ observado por Tullio (2004), para os animais terminados em confinamento, foi de 15,56, semelhante ao deste ensaio. Porém, quando considerada a condição sexual, este autor observou diferença entre os tourinhos, que apresentaram valor médio de 14,97, e os castrados de 16,11. Não foi verificada diferença $(\mathrm{P}>0,05)$ para a intensidade de amarelo (b*), sendo os valores mais baixos que os observados por Abularach et al. (1998) e Tullio (2004), 6,12 e 3,29, respectivamente.

Tabela 5. Características da cor da carne e da gordura do contrafilé de bovinos Canchim terminados em confinamento, segundo o tratamento

\begin{tabular}{|c|c|c|c|c|c|c|c|c|}
\hline \multirow{2}{*}{ Característica } & \multicolumn{3}{|c|}{ Condição sexual } & \multirow[b]{2}{*}{$\mathrm{P}$} & \multicolumn{2}{|c|}{ Dieta } & \multirow{2}{*}{$P$} & \multirow{2}{*}{$\mathrm{CV}(\%)$} \\
\hline & $\mathrm{T}$ & $\mathrm{MC}$ & FM & & SM & $\mathrm{CA}$ & & \\
\hline \multicolumn{9}{|l|}{ Carne } \\
\hline $\mathrm{L}^{* 1}$ & $37,91 \pm 1,17$ & $37,78 \pm 2,00$ & $37,39 \pm 1,99$ & 0,81 & $37,98 \pm 1,55$ & $37,40 \pm 1,88$ & 0,40 & 5,01 \\
\hline$a^{*}$ & $15,33 \pm 1,23$ & $15,52 \pm 1,44$ & $15,92 \pm 1,07$ & 0,58 & $15,86 \pm 1,32$ & $15,32 \pm 1,17$ & 0,25 & 8,18 \\
\hline $\mathrm{b}^{*}$ & $2,88 \pm 0,83$ & $2,91 \pm 1,04$ & $2,97 \pm 0,88$ & 0,97 & $3,20 \pm 0,90$ & $2,64 \pm 0,94$ & 0,11 & 31,90 \\
\hline \multicolumn{9}{|l|}{ Gordura } \\
\hline $\mathrm{L}^{*}$ & $69,66 \pm 3,32$ & $69,09 \pm 2,85$ & $68,93 \pm 2,05$ & 0,83 & $69,44 \pm 3,02$ & $69,02 \pm 2,45$ & 0,69 & 4,10 \\
\hline$a^{*}$ & $5,45 \pm 1,71$ & $5,22 \pm 2,05$ & $6,10 \pm 1,93$ & 0,58 & $5,19 \pm 2,12$ & $6,00 \pm 1,67$ & 0,26 & 34,97 \\
\hline$b^{*}$ & $7,49 \pm 1,37$ & $8,17 \pm 1,58$ & $7,85 \pm 1,11$ & 0,55 & $7,20 \pm 1,36 b$ & $8,47 \pm 1,34 \mathrm{a}$ & 0,02 & 17,80 \\
\hline
\end{tabular}

Médias seguidas de letras diferentes, na mesma linha, diferem entre si pelo teste Tukey $(\mathrm{P}<0,05)$

T: tourinho; MC: macho castrado; FM: fêmea.

SM: dieta com silagem de milho e concentrado contendo farelo de soja; CA: dieta com cana-de-açúcar e concentrado contendo farelo de soja e grãos de girassol.

P: probabilidade; CV: coeficiente de variação.

${ }^{1} L^{*}$ - luminosidade; $a^{*}$ - intensidade da cor vermelha; $b^{*}$ - intensidade da cor amarela.

A luminosidade e a coloração da carne são relacionadas diretamente com o valor de $\mathrm{pH}$ após o resfriamento. No caso deste estudo, em que os valores de $\mathrm{pH}$ permaneceram dentro dos limites ideais, as características de L*, a* e b* foram coerentes. De acordo com Pereira (2002), a intensidade de $a^{*}$ deve situar-se entre 18 e 22 , porém, em animais mais jovens, observa-se 
coloração mais clara. Conforme esse autor, o pigmento de mioglobina, que retém o oxigênio no músculo, torna-se menos eficiente em animais com maior idade e, para compensar, são produzidos níveis mais elevados de mioglobina, que aumentam a intensidade da cor vermelha. Isso contrasta com os resultados do presente experimento, que usou animais jovens, portanto com carne de coloração cereja, também bastante apreciada pelo consumidor.

Com relação a b* da gordura, os animais que receberam dieta contendo cana-de-açúcar apresentaram gordura mais amarelada $(\mathrm{P}<0,05)$ que os alimentados com dieta contendo silagem de milho. Este resultado pode estar relacionado com a ingestão de pigmentos carotenóides contidos no volumoso verde. Tullio (2004) relatou que os animais terminados no pasto apresentaram intensidade do croma $b^{*}$ da gordura maior que os animais em confinamento. A coloração amarelada da gordura normalmente está associada a um animal produzido no pasto, portanto com maior idade de abate, enquanto a gordura menos pigmentada (branca) está relacionada a animais acabados em confinamento, em que normalmente a fração volumosa da dieta é pobre em pigmentos carotenóides.

Os resultados da análise sensorial, apresentados na Tab. 6, não demonstraram efeitos da interação $(\mathrm{P}>0,05)$ da condição sexual e dieta. Não foram observadas diferenças entre as dietas.

Tabela 6. Análise sensorial por painel de degustação da carne do contrafilé de bovinos Canchim terminados em confinamento, segundo o tratamento

\begin{tabular}{|c|c|c|c|c|c|c|c|c|}
\hline \multirow{2}{*}{$\begin{array}{c}\text { Característica } \\
\text { sensorial }\end{array}$} & \multicolumn{3}{|c|}{ Condição sexual } & \multirow[b]{2}{*}{$\mathrm{P}$} & \multicolumn{2}{|c|}{ Dieta } & \multirow[b]{2}{*}{$\mathrm{P}$} & \multirow[b]{2}{*}{$\mathrm{CV} \%$} \\
\hline & $\mathrm{T}$ & $\mathrm{MC}$ & FM & & SM & $\mathrm{CA}$ & & \\
\hline Sabor & $7,07 \pm 1,30$ & $7,33 \pm 1,28$ & $7,40 \pm 1,28$ & 0,38 & $7,37 \pm 1,14$ & $7,17 \pm 1,43$ & 0,33 & 17,92 \\
\hline Textura & $6,46 \pm 1,63 b$ & $7,48 \pm 1,35 \mathrm{a}$ & $7,31 \pm 1,71 \mathrm{a}$ & 0,02 & $7,17 \pm 1,35$ & $7,00 \pm 1,78$ & 0,49 & 22,60 \\
\hline Aparência & $7,12 \pm 1,24$ & $7,31 \pm 1,24$ & $7,16 \pm 1,35$ & 0,73 & $7,25 \pm 1,26$ & $7,14 \pm 1,29$ & 0,58 & 17,88 \\
\hline Aspecto geral & $6,87 \pm 1,32$ & $7,38 \pm 1,16$ & $7,24 \pm 1,35$ & 0,10 & $7,24 \pm 1,12$ & $7,08 \pm 1,43$ & 0,43 & 18,12 \\
\hline
\end{tabular}

Médias seguidas de letras diferentes, na mesma linha, diferem entre si pelo teste Kruskal-Wallis $(\mathrm{P}<0,05)$.

T: tourinho; MC: macho castrado; FM: fêmea.

SM: dieta com silagem de milho e concentrado contendo farelo de soja; CA: dieta com cana-de-açúcar e concentrado contendo farelo de soja e grãos de girassol.

$\mathrm{P}$ : probabilidade; CV: coeficiente de variação.

$\mathrm{Na}$ análise do painel sensorial, não houve diferença quanto à condição sexual, para as características de sabor, aparência e aspecto geral das amostras de contrafilé. Os machos castrados e as fêmeas apresentaram melhor classificação $(\mathrm{P}<0,05)$ no painel sensorial quanto à textura, que, entre todas as características sensoriais, é a mais importante. Segundo Luchiari Filho (2000), essa característica é determinante da qualidade da carne. Este resultado pode estar relacionado com a gordura de cobertura da carcaça dos machos castrados e das fêmeas. Embora não tenham sido observadas diferenças estatísticas com relação a essa variável, a EGC das fêmeas e dos machos castrados foram, respectivamente, $18,9 \%$ e $23,2 \%$ mais altos que a dos tourinhos, quando considerados os valores absolutos das médias. Conforme Pereira (2000), a gordura de cobertura apresenta importante função de proteger a carcaça das baixas temperaturas observadas nas câmaras frigoríficas; dessa forma, camadas mais espessas de gordura são mais efetivas como isolante térmico, minimizando o encurtamento de fibras musculares causado pela queda brusca de temperatura na superfície do músculo, com conseqüências negativas à maciez e textura da carne.

\section{CONCLUSÕES}

Tourinhos, machos castrados e fêmeas da raça Canchim são indicados para produção de bovinos jovens em sistemas intensivos. A textura da carne de machos castrados e fêmeas foi melhor que a de tourinhos, sendo a carne dos animais considerada macia em todos os tratamentos. As dietas SM e CA são eficientes para a terminação de bovinos confinados com vistas à qualidade da carcaça e da carne. 


\section{REFERÊNCIAS BIBLIOGRÁFICAS}

ABULARACH, M.L.S.; ROCHA, C.E.; FELÍCIO, P.E. Características de qualidade do contrafilé (m.L.dorsi) de touros jovens da raça Nelore. Cien. Tecnol. Alim., v.18, p.205-210, 1998.

ARRIGONI, M.B. Eficiência produtiva de bovinos de corte no modelo biológico superprecoce. 2003. 428f. Tese (Livre Docência) - Faculdade de Medicina Veterinária e Zootecnia, Universidade Estadual Paulista, Botucatu, SP.

BERG, R.T.; BUTTERFIELD, R.M. New concepts of cattle growth. 5.ed. Sydney: Sydney University, 1976. 240p.

BRONDANI, I.L.; RESTLE, J.; ARBOITTE, M.Z.; et al. Efeito de dietas que contém cana-de-açúcar ou silagem de milho sobre as características de carcaça de novilhos confinados. Cien. Rural, v.36, p.197202, 2006

CRUZ, G.M. Avaliação qualitativa e quantitativa da carcaça de bovinos. In: ESTEVES, S.N. Intensificação da bovinocultura de corte: estratégias de alimentação e terminação. São Carlos: Embrapa-CPPSE, 1997. p.58-75, (Embrapa-CPPSE. Documentos, 27).

FOX, D.G.; SNIFFEN, C.J.; O'CONNOR, J.D. A net carbohydrate and protein system for evaluating cattle diets: III Cattle requirements and diets adequacy. J. Anim. Sci., v.70, p.3578-3596, 1992.

GREGORY, N.G. Animal welfare and meat science. Cambridge: University Press, 1998. 289p.

HENRIQUE, W.; SAMPAIO, A.A.M.; LEME, P.R. et al. Desempenho e características de carcaça de tourinhos Santa Gertrudes confinados, recebendo dietas com alto concentrado e níveis crescentes de polpa cítrica peletizada. Rev. Bras. Zootec., v.33, p.463-470, 2004.

JORGE, A.M.; FONTES, C.A.A.; PAULINO, M.F. et al. Desempenho produtivo de animais de quatro raças zebuínas, abatidos em três estádios de maturidade 2. Características de carcaça. Rev. Bras. Zootec., v.28, p.381-387, 1999.

JUNQUEIRA, J.O.B.; VELLOSO, L.; FELÍCIO, P.E. Desempenho, rendimento de carcaça e cortes de animais, machos e fêmeas, mestiços Marchigiana $\mathrm{x}$ Nelore, terminados em confinamento. Rev. Bras. Zootec., v.27, p.1199$1205,1998$.
LANDELL, M.G.A.; CAMPANA, M.P.; RODRIGUES, A.A. et al. A variedade IAC84-2480 como nova opção de cana-de-açucar para fins forrageiros: manejo de produção e uso na alimentação animal. Boletin Técnico IAC 193, Campinas: Instituto Agronômico, 2002. 39p.

LAWRIE, R.A. Ciência da carne. 6.ed. Porto Alegre: Artmed, 2005. 384p.

LUCHIARI FILHO, A. A pecuária da carne bovina. São Paulo: A. Luchiari Filho, 2000. 134p.

NARDON, R.F.; RAZOOK, A.G.; SAMPAIO, A.A.M. et al. Efeito da raça e seleção para peso pós-desmama no desempenho de bovinos em confinamento. Bol. Ind. Anim., v.58, p.21-34, 2001.

PEREIRA, A.S.C. Qualidade da carne de bovinos Nelore (Bos taurus indicus) suplementados com vitamina E. 2002. 83f. Dissertação (Mestrado em Zootecnia) - Faculdade de Zootecnia e Engenharia de Alimentos, Universidade de São Paulo, Pirassununga, SP.

RIBEIRO, F.G.; LEME, P.R.; BULLEM, M.L.M. et al. Características da carcaça e qualidade da carne de tourinhos alimentados com dietas de alta energia. Rev. Bras. Zootec., v.31, p.749-756, 2002.

RESTLE, J.; CERDOTES, L.; VAZ, F.N. et al. Características de carcaça e da carne de novilhas Charolês e $3 / 4$ Charolês $1 / 4$ Nelore, terminadas em confinamento. Rev. Bras. Zootec., v.30, supl. 1, p.1065-1075, 2001.

SAMPAIO, A.A.M.; BRITO, R.M.; VIEIRA, P.F. et al. Efeito da suplementação protéica sobre o crescimento, terminação e viabilidade econômica de bezerros mestiços Canchim confinados pósdesmama. Rev. Bras. Zootec., v.27, p.823-831, 1998.

SAMPAIO, I.B.M. Estatística aplicada à experimentação animal. 2.ed. Belo Horizonte: FEPMVZ, 2002. 221p.

TULliO, R.R. Estratégias de manejo para produção intensiva de bovinos visando à qualidade da carne. 2004. 107f. Tese (Doutorado em Zootecnia) - Faculdade de Ciências Agrárias e Veterinárias, Universidade Estadual Paulista, Jaboticabal, SP.

VAZ, F.N.; RESTLE, J. Características de carcaça e da carne de novilhos Hereford, terminados em confinamento com diferentes fontes de volumoso. Rev. Bras. Zootec., v.34, p.230-238, 2005. 